\title{
Prevalência e fatores associados a marcadores do vírus da hepatite $B$ em população rural do Brasil central
}

\author{
Francisco J. D. Souto, ${ }^{1}$ Graciela A. Espírito Santo, ${ }^{1}$ Juliano C. Philippi, ${ }^{1}$ \\ Bruno R. C. Pietro, ${ }^{1}$ Renato B. Azevedo ${ }^{1}$ e Ana M. C. Gaspar ${ }^{2}$
}

RESUMO Objetivo. Realizar um inquérito soro-epidemiológico sobre infecção pelo vírus da hepatite B em um município do médio-norte do Estado de Mato Grosso, que corresponde à região limítrofe entre o cerrado e a bacia amazônica.

Métodos. A amostra incluiu famílias escolhidas aleatoriamente na sede do município, assim como toda a população de uma comunidade rural, totalizando 754 indivíduos. A idade variou de 2 a 79 anos. Os participantes foram entrevistados e tiveram amostras de sangue colhidas para pesquisa de marcadores do vírus da hepatite $B$ por método imunoenzimático.

Resultados. A infecção pelo vírus da hepatite B foi constatada em $31 \%$ da amostra, sendo $3 \%$ positivos para o HBsAg. Os 149 (20\%) com história de vacinação e anti-HB positivo isoladamente foram considerados respondedores à vacina. As variáveis associadas à exposição ao vírus da hepatite B por análise multivariada foram: já ter iniciado atividade sexual, ter sido vacinado com pistola pressurizada contra febre amarela (entre aqueles com menos de 20 anos) $e$ ser migrante oriundo do Sul do Brasil (indivíduos com mais de 20 anos). A cobertura vacinal foi baixa entre indivíduos com mais de 10 anos de idade. O maior número de suscetíveis (74\%) foi encontrado na faixa dos 11 aos 20 anos.

Conclusões. No Brasil, a vacinação contra a hepatite $B$ deve ser estendida quanto antes aos adolescentes nas regiões de baixa a moderada prevalência. É provável que os dados obtidos no presente estudo possam ser extrapolados para outras regiões da América Latina com padrão epidemiológico semelhante.

Palavras chave Vacinação, infecção/prevenção e controle.

A infecção pelo vírus da hepatite B (VHB) é um importante problema de saúde pública em todo o mundo, espe-

1 Universidade Federal de Mato Grosso, Departamento de Clínica Médica, Núcleo de Estudos de Doenças Infecciosas e Tropicais, Cuiabá, MT, Brasil. Correspondência e pedidos de separatas devem ser enviados a Francisco J. D. Souto no seguinte endereço: Rua W2, Quadra 3, Número 2, Bela Marina, CEP 78070-720, Cuiabá, MT, Brasil. Telefone: +55-65-615-7302; fax: +55-65-642-1093; e-mail: fsouto@terra.com.br

2 Instituto Oswaldo Cruz, Departamento de Virologia, Centro Nacional de Referência para Hepatites Virais, Rio de Janeiro, RJ, Brasil. cialmente entre os países em desenvolvimento. No Brasil, a bacia amazônica é a região de mais alta prevalência desta infecção (1). Outras regiões brasileiras com alta prevalência do VHB são parte do Estado do Espírito Santo e o oeste dos Estados do Paraná e de Santa Catarina (2).

O Estado de Mato Grosso é uma vasta área localizada no centro do continente sul-americano, que engloba o sul da bacia amazônica (figura 1). Estudos recentes mostraram que o sul de Mato
Grosso, de colonização mais antiga, apresenta baixa prevalência da infecção pelo VHB. Os marcadores de infecção pelo VHB estão presentes em $20 \%$ da população (3). Já a porção amazônica do estado, colonizada mais recentemente, atrai migrantes de outras regiões do país, tem condições higiênico-sanitárias precárias e apresenta índices bem mais elevados de infecção pelo VHB, que variam de 54 até $75 \%(4,5)$.

O médio-norte mato-grossense fica localizado entre as duas regiões descri- 
FIGURA 1. Mapa do Brasila

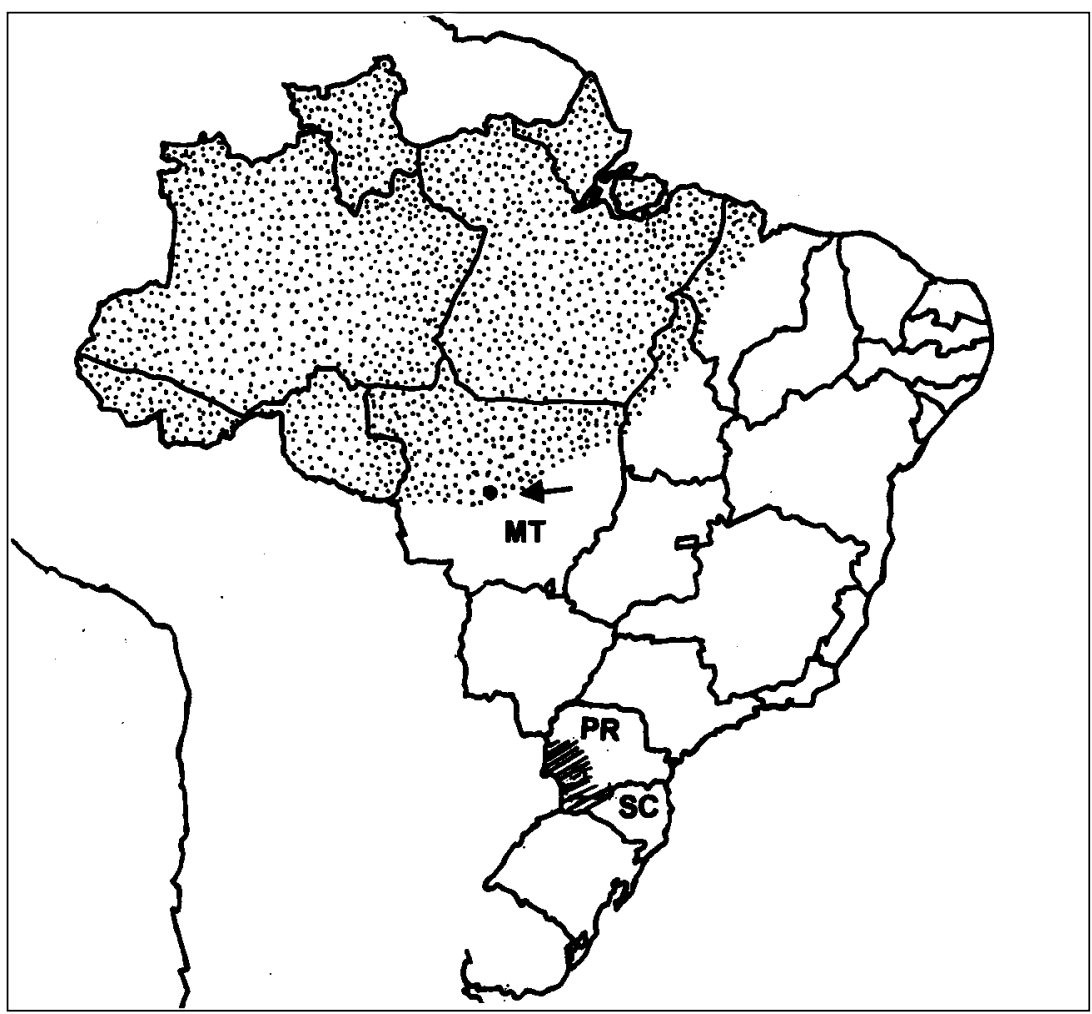

a A área salpicada representa a bacia amazônica. A área hachurada corresponde às áreas de prevalência moderada a alta de hepatite B no Sul do país. MT: Estado de Mato Grosso; PR: Estado do Paraná; SC: Estado de Santa Catarina.

tas acima. É uma importante área agrícola em expansão, colonizada nas últimas décadas por migrantes vindos de outras regiões do Brasil. Trata-se de uma região caracterizada por alta taxa de crescimento populacional anual ( $9 \%)$, como conseqüência de expansão da agricultura mecanizada (6). O médio-norte mato-grossense é uma região de transição entre o cerrado (planalto central brasileiro) e a floresta amazônica, em cujos municípios nunca se realizou inquérito soro-epidemiológico de hepatites virais.

Conhecer os níveis da infecção pelo VHB nessa região é importante pela sua proximidade com a Amazônia e pela origem de seus habitantes, muitos dos quais vieram de outra região com prevalência moderada a alta - o oeste dos Estados do Paraná e Santa Catarina $(2,7,8)$. Com o intuito de estimar a prevalência de marcadores do VHB na região médio-norte de Mato
Grosso, realizou-se, em 1999, um inquérito soro-epidemiológico no Município de Nova Mutum. O histórico de migração dos participantes foi registrado para análise da influência da origem dos habitantes na prevalência de exposição ao VHB. Também foi investigada a situação vacinal dos participantes, uma vez que a vacina contra o VHB em crianças foi introduzida como parte do Programa Nacional de Imunizações no Brasil em 1997 (9).

\section{POPULAÇÃO E MÉTODOS}

O Município de Nova Mutum tem uma taxa de crescimento populacional anual de 15\% (6). Em 2000, contava com 14817 habitantes concentrados em um centro urbano e alguns pequenos vilarejos rurais. Foi escolhido o vilarejo denominado Ranchão para representar a população rural, compre- endendo 115 famílias. Para representar o núcleo urbano, foram escolhidos três bairros de moradores com baixo poder aquisitivo, onde foram selecionadas, aleatoriamente, 115 moradias dentre as 372 destas comunidades, para comparação com a comunidade rural. Essas localidades foram escolhidas por serem servidas por equipe de programa de saúde da família da secretaria de saúde do município. Conseqüentemente, estão melhor mapeadas e são melhor conhecidas.

Todos os indivíduos com idade igual ou superior a 2 anos foram considerados elegíveis para o estudo. As razões para a realização do estudo e sua metodologia foram explicadas aos habitantes selecionados. Para os que aceitaram participar, foi solicitado que dessem consentimento por escrito. $\mathrm{O}$ projeto de pesquisa foi aprovado pelo comitê de ética em pesquisa em seres humanos do Hospital Júlio Muller, Universidade Federal de Mato Grosso.

Todos os indivíduos foram entrevistados para obtenção de dados epidemiológicos e demográficos e tiveram amostras de sangue coletadas para testes sorológicos. Alíquotas de soro foram congeladas, devidamente acondicionadas e enviadas ao departamento de virologia do Instituto Oswaldo Cruz, Fundação Oswaldo Cruz, Rio de Janeiro. Pesquisou-se, pelo método de ensaio imunoenzimático (ELISA), a presença do antígeno de superfície do VHB (HBsAg), de seu anticorpo correspondente (anti-HBs) e de anticorpos totais (da classe IgG) contra a proteína central do VHB (anti-HBc). Foram utilizados kits comerciais (Organon Teknika-Hepanostika, Boxtel, Holanda). Os resultados dos testes foram considerados de forma qualitativa. As amostras positivas para HBsAg foram subtipadas com anticorpos monoclonais anti-HBs específicos, conforme técnica padronizada e descrita anteriormente (10).

Foram considerados como já tendo sido infectados pelo VHB os indivíduos com anti-HBc positivo, com ou sem positividade para HBsAg ou antiHBs. Para efeito de análise da resposta à vacina, foram considerados como respondedores os indivíduos anti-HBs 
positivos, sem HBsAg ou anti-HBc, que tivessem história de terem sido vacinados contra o VHB.

Os dados obtidos foram armazenados em banco de dados criado com o programa Epi Info 6.04a (11). O teste do qui-quadrado $\left(\chi^{2}\right)$ foi utilizado para comparar proporções. Quando apropriado, foi utilizado o teste exato de Fisher. A razão de chances (odds ratio, OR) também foi calculada, com o respectivo intervalo de confiança de $95 \%$. Modelos de regressão logística pelo método passo a passo (stepwise) foram construídos para análise multivariada, utilizando-se o programa Stata 6.0 para Windows (12). Foram incluídas nesses modelos variáveis que tivessem probabilidade de associação superior a $80 \%$. Foram consideradas como variáveis dependentes: 1) exposição ao VHB (antiHBc-positivo isolado); 2) ser portador do VHB (HBsAg-positivo). O modelo final foi repetido para diferentes faixas etárias, no intuito de identificar variáveis associadas especificamente a determinados grupos. Todos os cálculos foram considerados como tendo significância estatística quando a probabilidade $(P)$ de a hipótese nula ser verdadeira era menor do que 0,05 .

\section{RESULTADOS}

De 825 indivíduos elegíveis nas 230 habitações da amostra, 754 (92\%) foram incluídos no estudo. A perda de amostra foi determinada por falha na coleta de sangue ou por recusa a participar. A perda foi maior na comunidade rural, mas não diferiu quanto à distribuição por idade ou gênero quando comparada à perda sofrida na outra comunidade.

Dos 754 participantes, 399 (53\%) eram do sexo feminino, com idade variando de 2 a 79 anos (média de 22,8 anos e mediana de 19 anos). Trezentos e quatro $(40 \%)$ participantes eram imigrantes, sendo 140 procedentes da região oeste de Santa Catarina ou do Paraná. Grande parte dos não-migrantes eram filhos de migrantes, nascidos depois da chegada na região do estudo.

Do total incluído, 232 (31\%; IC95\% = 27-34) já haviam sido infectados pelo
FIGURA 2. Prevalência dos marcadores do vírus da hepatite B por grupos etários, Nova Mutum (MT), Brasil, 1999a

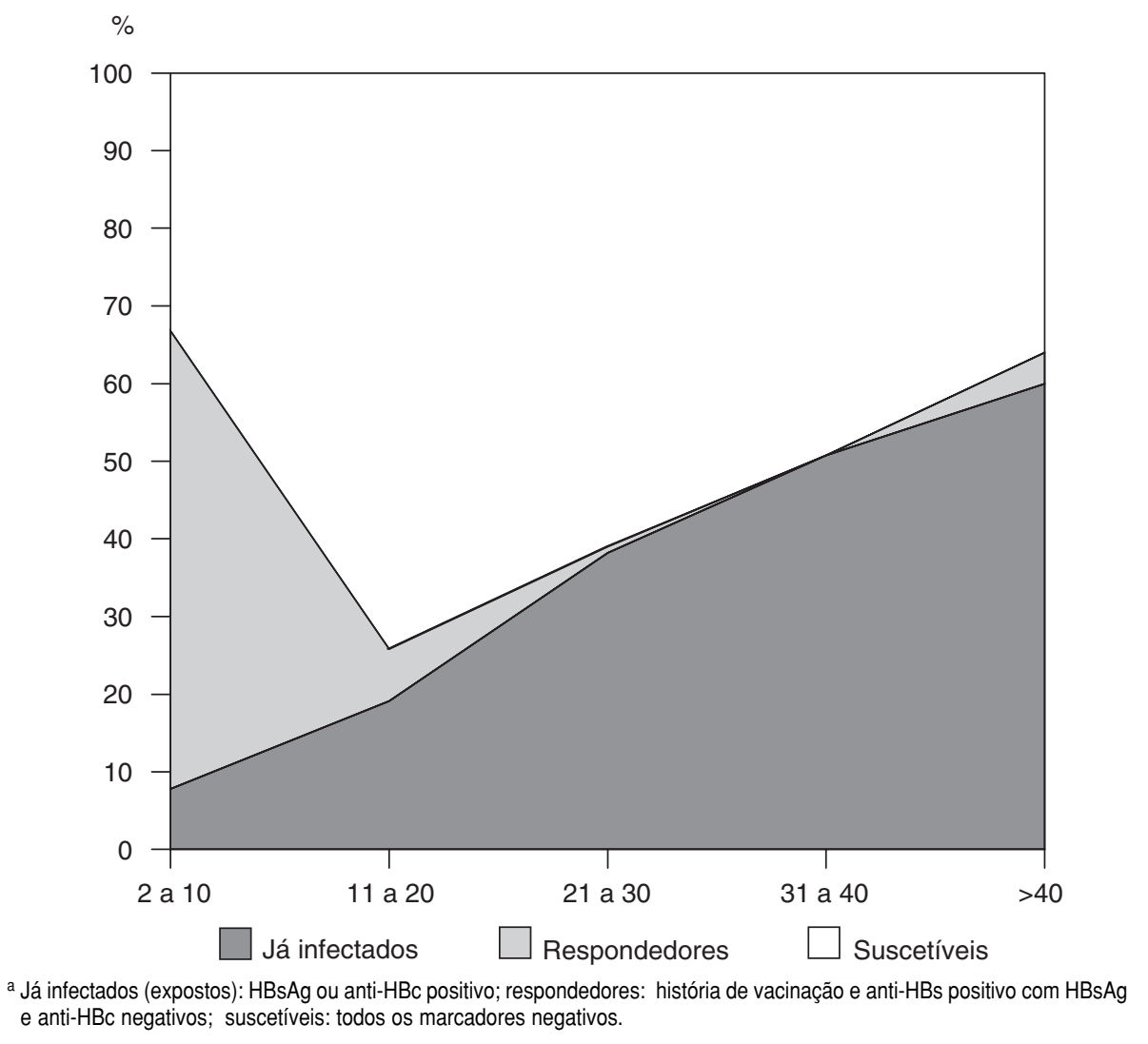

VHB, sendo que 19 (3\%; IC95\% = 2-4) eram portadores do HBsAg. Foram considerados respondedores $149(20 \%$, IC95\% = 17-23) indivíduos que foram positivos para o anti-HBs isoladamente. Os outros 373 (50\%; IC $95 \%=$ 46-53) eram ainda suscetíveis ao VHB (figura 2). Dos 17 indivíduos HBsAgpositivos, em 10 foi possível identificar os subtipos do HBsAg: ayw3 em cinco; ayw2 em três; adw2 em dois; e adw4 em um. Os cinco indivíduos com subtipo ayw3 eram originários da região Sul do país, enquanto que os três com subtipo adw eram oriundos da Amazônia.

Os migrantes procedentes do oeste paranaense e catarinense apresentavam maior prevalência de marcadores de infecção pelo VHB do que o resto da amostra ( $52 \%$ versus $26 \%$; $P=$ 0,0001 , tabela 1 ). Os marcadores de exposição ao VHB foram mais comuns na população urbana ( $34 \%$ versus $26 \%$; $P=0,02)$. Não houve diferença na pre- valência da exposição ao VHB por gênero. Com o aumento da idade, houve incremento da prevalência de marcadores de infecção pelo VHB (figura 2). O efeito da idade foi bastante nítido na segunda e terceira décadas de vida, especialmente a partir dos 15 anos de idade (figura 3).

Dos 217 participantes com até 10 anos, $81 \%$ já haviam recebido pelo menos uma dose da vacina. A maior concentração de suscetíveis foi encontrada entre os jovens de 11 a 20 anos (74\%). Nessa faixa etária havia indivíduos vacinados apenas até os 15 anos. O segundo grupo com maior número de suscetíveis foi o de indivíduos entre 21 e 30 anos (61\%). Como era esperado, a maior concentração de respondedores $(59 \%)$ foi observada entre aqueles com até 10 anos (figura 2). Nessa faixa etária, apenas $33 \%$ eram suscetíveis ao VHB.

Após a análise univariada, não foi identificada associação das variáveis 
TABELA 1. Distribuição dos marcadores do vírus da hepatite B por faixa etária e procedência de migração, Município de Nova Mutum (MT), Brasil, 1999a

\begin{tabular}{llrlrl}
\hline $\begin{array}{c}\text { Faixa etária } \\
\text { (anos) }\end{array}$ & $\begin{array}{c}\text { Infecção pelo } \\
\text { VHB/Total (\%) }\end{array}$ & $\begin{array}{r}\text { Expostos ao } \\
\text { VHB/Total migrantes } \\
\text { do oeste PR/SC (\%) }\end{array}$ & $\begin{array}{r}\text { Expostos ao VHB/Total } \\
\text { outros migrantes } \\
\text { + nascidos em MT }\end{array}$ & $P^{\text {b }}$ \\
\hline $2-10$ & $17 / 217(8)$ & $2 / 23(9)$ & $15 / 194(8)$ & 0,8 \\
$11-20$ & $34 / 178(19)$ & $3 / 18(17)$ & $31 / 160(19)$ & 0,9 \\
$21-30$ & $50 / 131(38,2)$ & $13 / 25(52)$ & $37 / 106(35)$ & 0,2 \\
$31-40$ & $70 / 117(60)$ & $29 / 43(67)$ & $41 / 74(55)$ & 0,3 \\
Mais de 40 & $67 / 111(60)$ & $26 / 31(84)$ & $41 / 74(44)$ & $<0,0001$ \\
Total & $232 / 754(31)$ & $73 / 140(52)$ & $159 / 614(26)$ & $<0,0001$ \\
\hline
\end{tabular}

a VHB = Vírus da hepatite B; PR = Estado do Paraná; SC = Estado de Santa Catarina; MT = Estado de Mato Grosso.

${ }^{b}$ Valor de $P$ para $\chi^{2}$ de tendência $=0,00001$. "exposição ao VHB" ou "ser portador do HBsAg" com a situação econômica, o tempo vivendo na região estudada, o passado de doença sexualmente transmitida, o uso de drogas endovenosas e a presença de tatuagem. As variáveis "ter recebido transfusão de sangue" $(P<0,05)$, "ter sofrido cirurgia" $(P<$ $0,0000)$ ou "ter recebido vacina por pistola pressurizada" $(P=0,0001)$ foram todas associadas à exposição ao VHB. Essas associações não se mantiveram quando analisados apenas os indivíduos com mais de 20 anos.

Os migrantes oriundos do oeste de Santa Catarina e Paraná tiveram prevalência mais elevada de exposição ao VHB quando comparados ao restante da amostra ( $52 \%$ versus $26 \%$; OR $=3,1$; IC $95 \%=2,1-4,6 ; P<0,0001)$. Porém, na estratificação por grupos etários, a diferença só foi significativa entre os indivíduos acima de 30 anos. A variável "ter iniciado atividade sexual" também foi associada à exposição ao VHB $(P<0,0000)$, mas não entre aqueles com mais de 30 anos.

Na análise multivariada não se identificou qualquer variável associada à condição de portador (HBsAg positivo). No entanto, ter iniciado atividade sexual, ter vivido no oeste de Santa Catarina ou Paraná, ter sofrido vacinação com pistola pressurizada e ser de faixa etária mais alta mostraram associações estatisticamente significativas com a infecção pelo VHB (tabela 2). Quando esse mesmo modelo foi analisado considerando apenas os indivíduos entre 11 e 20 anos de idade, as variáveis associadas foram a vacinação com pistola pressurizada e a atividade sexual (tabela 2). Quando o modelo foi considerado para a população acima de 20 anos, apenas a variável "ter vivido no oeste de Santa Catarina ou Paraná" permaneceu associada à infecção pelo VHB (tabela 2).

\section{DISCUSSÃO}

Este é o primeiro estudo referente à prevalência de marcadores da hepatite
B na região médio-norte do Estado de Mato Grosso, área de transição entre a Amazônia e o planalto central brasileiro, colonizada por migrantes de outras regiões brasileiras. É também um dos primeiros estudos de prevalência de marcadores de hepatite $B$, com amostra populacional representativa, desde que o governo brasileiro estendeu a vacinação contra o VHB em crianças em todo o território nacional, em 1997.

A prevalência de marcadores sorológicos de infecção pelo VHB encontrada na amostra estudada em Nova Mutum pode ser classificada como moderada (31\% já expostos, com $3 \%$ de portadores do HBsAg) (13). Esses dados sugerem que o médio-norte de Mato Grosso se comporta, quanto à prevalência da hepatite $B$, como área de transição entre o sul (prevalência baixa) e o norte (moderada a alta) do estado (3-5).

Em Mato Grosso, nas comunidades assentadas mais ao norte, quanto maior o tempo na área de colonização, maior a exposição ao $\mathrm{VHB}(4,5)$. Esse fenômeno não foi verificado no presente estudo, provavelmente devido a um melhor planejamento socioeconôFIGURA 3. Prevalência de marcadores de exposição prévia ao VHB por idade entre indiví-
duos na segunda década de vida, Nova Mutum (MT), Brasila

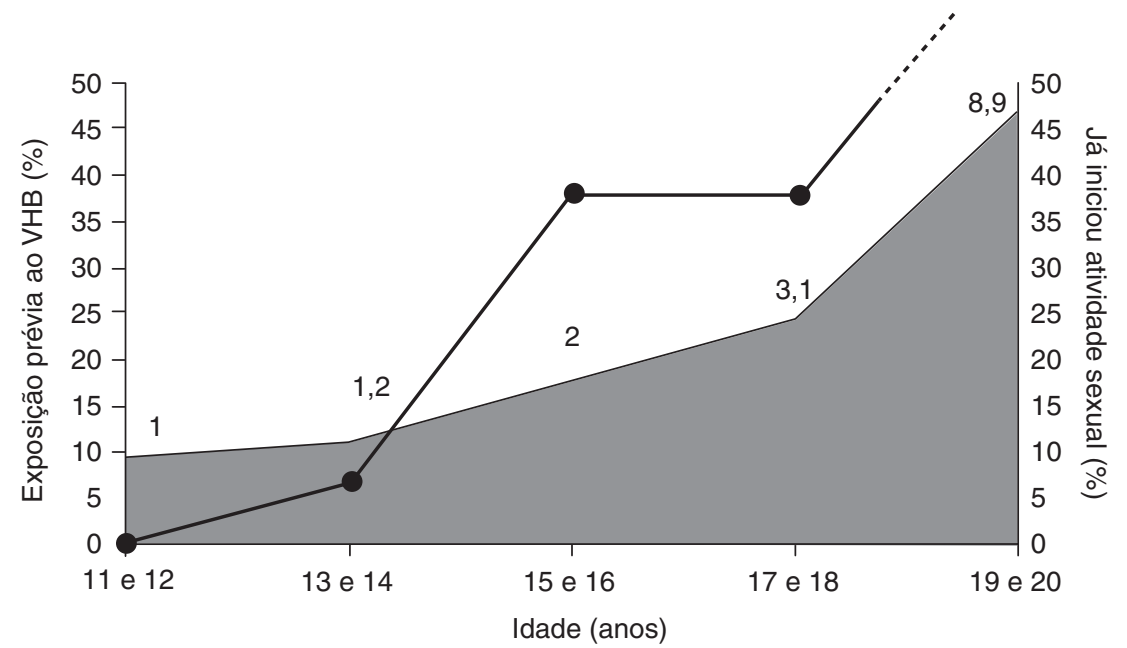

a Números ao longo da curva correspondem às razões de chances $(\mathrm{OR})$ em análise de tendência $(P<0,0001)$. A linha contínua (cinza) demonstra a prevalência de indivíduos que já haviam tido atividade sexual. Número de indivíduos em cada grupo etário: 11-12 anos, 43; 13-14 anos, 46; 15-16 anos, 29; 17-18 anos, 37; e 19-20 anos, 23 indivíduos. 
TABELA 2. Análise multivariada de fatores demográficos e de risco de exposiçãoa ao vírus da hepatite B, Nova Mutum (MT), Brasil, 1999

\begin{tabular}{|c|c|c|c|c|c|c|}
\hline Variáveis & \multicolumn{2}{|c|}{ Modelo $1^{\mathrm{b}}(n=725)$} & \multicolumn{2}{|c|}{ Modelo $2^{c}(n=484)$} & \multicolumn{2}{|c|}{ Modelo $3^{\mathrm{d}}(n=220)$} \\
\hline \multicolumn{7}{|l|}{ Idade (anos) } \\
\hline $11-20$ & $1,8(0,8-3,7)$ & 0,1 & & & & \\
\hline $21-30$ & $3,4(1,4-8,2)$ & $<0,001$ & & & & \\
\hline $31-40$ & $8,1(3,2-20,1)$ & $<0,001$ & & & & \\
\hline \multicolumn{7}{|c|}{ Atividade sexual } \\
\hline Não & 1,0 & - & 1,0 & & 1,0 & - \\
\hline Sim & $1,8(1,1-3,2)$ & $<0,05$ & $3,7(2,1-6,5)$ & $<0,001$ & $1,0(0,4-2,4)$ & 0,9 \\
\hline \multicolumn{7}{|c|}{ Migrante do Sul } \\
\hline Não & 1,0 & - & 1,0 & - & 1,0 & - \\
\hline Sim & $2,6(1,7-4,1)$ & $<0,001$ & $1,6(0,8-3,2)$ & 0,2 & $3,9(2,0-7,5)$ & $<0,001$ \\
\hline \multicolumn{7}{|l|}{ Zona rural } \\
\hline \multicolumn{7}{|l|}{ Transfusão } \\
\hline Não & & - & 1,0 & - & 1,0 & - \\
\hline Sim & $1,5(0,7-3,2)$ & 0,3 & $1,8(0,4-6,9)$ & 0,4 & $1,2(0,5-3,1)$ & 0,7 \\
\hline
\end{tabular}

a Desfecho = Reatividade para o anti-HBc com HBsAg ou anti-HBs.

b Todas as idades.

${ }^{c}<30$ anos

d $>30$ anos

mico e infra-estrutural na colonização do médio-norte de Mato Grosso em relação à ocupação de regiões mais ao norte. Outra explicação poderia ser a intensa atividade de garimpos de ouro que existiu no norte do estado, já que os garimpeiros foram identificados como possíveis facilitadores da disseminação de doenças tropicais, como malária e hepatite $\mathrm{B}$, na Amazônia brasileira $(4,14,15)$. Por outro lado, fatores ambientais inerentes à selva tropical úmida podem também influenciar a circulação do VHB, uma vez que a doença pode se espalhar rapidamente na ausência de atividade de garimpo, como visto durante a epidemia comunitária no extremo noroeste de Mato Grosso (5).

Ser migrante do oeste do Paraná e de Santa Catarina associou-se significativamente à presença de marcadores de infecção pelo VHB. No entanto, tal associação não se apresentou na parcela da amostra com menos de 20 anos de idade. A separação entre migrantes e não-migrantes nos menores de 20 anos pode ser fator de confusão, uma vez que grande parte dos não-migrantes eram filhos de migrantes. De fato, os subtipos ayw do VHB, predominantemente encontrados entre os migrantes e seus descendentes, são os mais freqüentemente identificados na região Sul do Brasil (16). A maioria dos migrantes da área de estudo veio exatamente daquela região. Esse dado sugere que esses migrantes trouxeram consigo o VHB, o que também foi verificado em outras localidades receptoras de migrantes em Mato Grosso (4, 5, 15). Do mesmo modo, estudos em indivíduos que migraram de áreas de alta prevalência do VHB para países desenvolvidos mostraram que os migrantes apresentam perfil da infecção semelhante ao da população de seus países de origem $(17,18)$.

Ter recebido vacinação por pistola pressurizada foi fator associado à exposição ao VHB entre os mais jovens. Até os anos 1990, esse método de vacinação foi muito utilizado em certas regiões do Brasil, especialmente para vacinação em massa contra febre amarela. A região rural de Mato Grosso é endêmica para febre amarela e a vacinação é obrigatória. $\mathrm{O}$ uso da pistola pressurizada foi interrompido pelas autoridades sanitárias brasileiras, apesar de não terem sido encontradas evidências que incriminassem tal prática na transmissão de doenças $(19,20)$. No entanto, a associação encontrada no presente estudo sugere que o aparelho pode ter facilitado a contaminação em parte desses indivíduos.

Já ter iniciado atividade sexual também esteve associado aos marcadores do VHB na análise multivariada. Essa variável foi a mais importante entre os jovens de 11 a 20 anos, o que está de acordo com o comportamento epidemiológico verificado em populações de prevalência baixa ou moderada para infecção pelo $\operatorname{VHB}(21,22)$. Tal padrão não é encontrado em populações de alta prevalência, nas quais a exposição ao VHB ocorre precocemente, já na primeira década de vida $(23,24)$. 
No presente estudo, constatou-se boa cobertura vacinal entre as crianças abaixo dos 10 anos. Essa faixa etária foi a que apresentou o menor número de suscetíveis na amostra, sugerindo que as novas coortes de brasileiros terão níveis endêmicos de infecção pelo VHB bem mais baixos do que os níveis atualmente observados em coortes nascidas antes dos anos 1990. No entanto, a baixa cobertura vacinal observada neste estudo a partir dos 11 anos de idade gera uma grande concen- tração de suscetíveis na segunda década de vida. Como é justamente nessa faixa etária que a transmissão do VHB se acelera, provavelmente por contágio sexual, as campanhas de vacinação e de esclarecimento a esses jovens seriam cruciais nesse momento. Tal estratégia já vem sendo proposta e instituída em outros países, por constações epidemiológicas semelhantes às que relatamos aqui (25-27). A nosso ver, a decisão de vacinar esses jovens é o próximo passo no combate ao VHB no país. É provável que essa seja uma realidade também em outros países latinoamericanos que tenham instituído a vacinação entre crianças recentemente.

Agradecimentos. Este projeto foi apoiado e parcialmente financiado pelo Centro Nacional de Epidemiologia, Fundação Nacional de Saúde, Ministério da Saúde do Brasil, através do projeto VIGISUS. Agradecemos ao Professor Cor Jésus Fernandes Fontes pela leitura crítica do texto.

\section{REFERÊNCIAS}

1. Torres JR. Hepatitis B and hepatitis delta virus infection in South America. Gut 1996;38(2 suppl):S48-S55.

2. Souto FJD 1999. Distribuição da hepatite B no Brasil: atualização do mapa epidemiológico e proposições para seu controle. Gastroenterol Endosc Digest 1999(4);18:143-150.

3. Souto FJD, Fontes CJF, Oliveira JM, Gaspar AMC, Lyra LGC. Epidemiological survey of infection with hepatitis B virus in the savannah and wetlands (Pantanal) of central Brazil. Ann Trop Med Parasitol 1997;91(4): 411-416.

4. Souto FJD, Fontes CJF, Gaspar AMC, Lyra LGC. Hepatitis B virus infection in immigrants to the southern Brazilian Amazon. Trans Royal Soc Trop Med Hyg 1998;92(3): 282-284.

5. Souto FJD, Fontes CJF, Gaspar AMC. Outbreak of hepatitis $B$ virus in recent arrivals to the Brazilian Amazon. J Med Virol 1998; 56(1):4-9.

6. Fundação Instituto Brasileiro de Geografia e Estatística (IBGE). Censo 2000 - resultados preliminares [site da Internet]. http://www. ibge.gov.br/ibge/default.php. Acessado em 7 de maio de 2001.

7. Estado de Santa Catarina, Central de Hematologia e Hemoterapia. Relatório anual de screening de candidatos a doadores de sangue. Santa Catarina; 1994.

8. Estado do Paraná, Instituto de Saúde do Paraná, Rede de Hemoterapia. Relatório anual de resultados de doadores de sangue. Paraná; 1994.

9. Fundação Nacional de Saúde. Programa Nacional de Imunizações [site da Internet]. http://www.funasa.gov.br/imu/imu01.htm. Acessado em 30 de abril de 2001.

10. Niel C, Moraes MTB, Gaspar AMC, Yoshida CFT, Gomes AS. Genetic diversity of hepati- tis B virus strains isolated in Rio de Janeiro, Brazil. J Med Virol 1994;44(2):180-186.

11. Dean JG, Dean JA, Coulombier D, Brendel KA, Smith DC, Burton AH, et al. Epi Info 6.04a: a Word processing database and statistics program for epidemiology on IBM compatible computers. Atlanta, Georgia: Centers for Disease Control and Prevention; 1996.

12. Intercooled Stata 6.0 for Windows 98/95/ NT. Texas, US: Stata Corporation; 1999.

13. Zuckerman JN, Zuckerman AJ. The epidemiology of hepatitis B. Clin Liver Dis 1999; 3(2):179-187.

14. Santos EO, Loreiro ECB, Jesus IM, Brabo E, Silva RSU, Soares MCP, et al. Diagnóstico das condições de uma comunidade garimpeira em uma região do Rio Tapajós, Itaituba, Pará, Brasil. Cad Saude Publ 1995; 11(2):212-225

15. Souto FJD, Fontes CJF, Gaspar AMC. Prevalence of hepatitis $B$ and $C$ virus markers among malaria-exposed gold miners in Brazilian Amazon. Mem Inst Oswaldo Cruz 2001;96(6):751-756.

16. Gaspar AMC, Yoshida CFT. Geographic distribution of HBsAg subtypes in Brazil. Mem Inst Oswaldo Cruz 1988(2);82:105-111.

17. Christenson B. Epidemiological aspects of the transmission of hepatitis B by HBsAgpositive adopted children. Scand J Infect 1986;18(2):105-109.

18. Tong MJ, Hwang SJ. Hepatitis B virus infection in Asian Americans. Gastroenterol Clin North Am 1994;23(3):523-536.

19. Evstigneev VI, Lukin EP. The safety of the jet (needle-free) injection. Voen Med Zh 1994; 79(7):38-39.

20. Sweat JM, Abdy M, Weniger BG, Harrington R, Covle B, Abuknesha RA, et al. Safety testing of needle free, jet injection devices to detect contamination with blood and other tissue fluids. Ann NY Acad Sci 2000;916: 681-682

21. Kane MA. Transmission of the hepatitis B virus in areas of low endemicity. Em: Piot $\mathrm{P}$ Andre FE, eds. Hepatitis B: a sexually transmitted disease in heterosexuals. Amsterdam Holland: Elsevier Science Publishers; 1990 p.9-13.

22. McQuillan GM, Townsend TR, Fields HA, Carroll M, Leahy M, Polk BF. Seroepidemiology of Hepatitis B virus infection in the United States-1976 to 1980. Am J Med 1989; 87(3 Suppl):5-10.

23. Bensabath G, Hadler S, Soares MC, Fields H, Maynard J. Características serológicas y epidemiológicas de la hepatitis vírica aguda en la cuenca amazónica del Brasil. Bol Of Sanit Panam 1987;103(4):351-356.

24. Blumberg BS. Feasibility of controlling or eradicating the hepatitis B virus. Am J Med 1989;87(3 suppl):2S-4S.

25. Centers for Disease Control and Prevention Hepatitis B Virus: A comprehensive strategy for eliminating transmission in the United States through universal childhood vaccination: recommendations of the Immunization Practices Advisory Committee (ACIP). MMWR 1991;40(RR-13):1-19.

26. Dobson F, Schifele D, Bell A. Assessment of a universal, school-based hepatitis B vaccination program. J Am Med Assoc 1995;274(15): 1209-1213.

27. Koff RS. Vaccines and hepatitis B. Clin Liver Dis 1999;3(2):417-427.

Manuscrito recebido em 27 de agosto de 2001. Aceito em 5 de setembro de 2001. 
ABSTRACT Objective. To carry out a survey of hepatitis B virus seroepidemiology in a municipality in central Brazil, on the border of two large ecosystems, the cerrado (savanna) and the Amazon River basin.

Prevalence of and factors associated with hepatitis $B$ virus markers in a rural population in central Brazil
Methods. The municipality studied, Nova Mutum, is located in the north central portion of the Brazilian state of Mato Grosso. The study sample of 754 individuals included persons from families, selected at random, who were living in the municipality's urban center as well as all the individuals living in a nearby rural village. Ages ranged from 2 to 79 years. All eligible individuals were interviewed. Blood was collected and used to assess hepatitis B virus markers by enzyme-linked immunosorbent assay.

Results. Hepatitis B virus infection was found in 232 individuals, or $31 \%$ of them; 19 of them (3\%) were HBsAg-positive. Of the 754 persons, 149 of them $(20 \%)$ who reported having been vaccinated against hepatitis B and who presented anti-HBs positivity were classified as vaccine responders. With the multivariate analysis, the variables found to be associated with exposure to hepatitis B virus were having begun sexual relations, having been vaccinated against yellow fever with a needle-free jet injection gun (for the age group $<20$ years), and being an immigrant from southern Brazil (> 20 years). Vaccine coverage was low among individuals older than 10 years. The largest share of susceptible individuals (74\%) were found in the age group of 11 to 20 years.

Conclusions. Our data suggest that hepatitis B virus vaccine coverage in Brazil should be extended to include teenagers in populations that have a low to moderate hepatitis B virus prevalence. It is likely that our results can be extrapolated to other areas of Latin America with a similar epidemiological pattern.

XXVI Reunión Anual de la
Asociación Argentina de Alergia e Inmunología Clínica
Fechas: 16 a 18 de agosto de 2002
Lugar: $\quad$ Buenos Aires, Argentina
Esta reunión, que se ha venido celebrando 25 años sin interrupción, es un importante
foro donde destacados alergólogos e inmunólogos de toda la América presentan los más re-
cientes adelantos en el campo de la inmunología. El propósito de la reunión es estimular la in-
vestigación y promover la educación continuada de especialistas en el ejercicio de su profesión.
Información:
Dr. Anahí Yánez o Dr. Hugo E. Neffen
Buenos Aires, Argentina
Tel.: (00 5411) 4331-7356
Correo electrónico: aaaei@speedy.com.ar
Website: http://www.alergia.org.ar

